\title{
GESTÃO PÚBLICA MUNICIPAL: ESTUDO DE CASO DO CONSELHO MUNICIPAL DE DIREITOS DA PESSOA COM DEFICIÊNCIA E ALTAS HABILIDADES DE PELOTAS/RS
}

\author{
GESTIÓN PÚBLICA MUNICIPAL: ESTUDIO DE CASO DEL \\ CONSEJO MUNICIPAL DE PERSONAS COM DISCAPACIDAD Y \\ ALTAS HABILIDADES DE PELOTAS/RS \\ MUNICIPAL PUBLIC MANAGEMENT: CASE STUDY OF THE \\ MUNICIPAL COUNCIL OF PERSONS WITH DISABILITIES AND \\ HIGH SKILLS OF PELOTAS/RS
}

\author{
Marco Aurelio Teixeira Silva ${ }^{1}$ \\ Igor Baptista de Oliveira Medeiros ${ }^{2}$
}

\begin{abstract}
Resumo
No Brasil, cerca de 45 milhões de pessoas possuem alguma deficiência, desse número, 26,5\% são mulheres e 21,2\% são homens (IBGE, 2010). Na cidade de Pelotas/RS para combater essas adversidades e ajudar a população deficiente foi criado em 1992 o Conselho Municipal de Direitos da Pessoa com Deficiência e Altas Habilidades, o primeiro do estado do Rio Grande do Sul e segundo do Brasil. Dado o breve exposto, a presente pesquisa objetiva analisar como ocorre a atuação do Conselho Municipal de Direitos da Pessoa com Deficiência e Alta Habilidade de Pelotas, visando à garantia dos direitos das pessoas com deficiência, bem como seu bem estar e qualidade de vida no município. Para tal, nosso estudo se concentra em um caráter qualitativo, no qual realizaremos uma investigação por meio entrevistas semiestruturadas à presidência do Conselho analisado. Assim, tendo como público-alvo as pessoas com deficiências da cidade de Pelotas, acreditamos que o conselho lhes garante/assegura seus direitos, proporcionando acesso à sociedade, por meio da garantia da inclusão social, familiar, acesso ao transporte, educação, saúde, prioridade em atendimento, segurança, acessibilidade, programas assistenciais, vagas no mercado de trabalho e etc. Por fim, ao longo da pesquisa, discorreremos sobre os problemas enfrentados pelo Conselho e sobre as mudanças na sociedade pelotense, visando direitos, cidadania e inclusão social da pessoa com deficiência.
\end{abstract}

Palavras-chave: Gestão pública; Conselho; Pessoa com deficiência.

\section{Resumen}

En el Brasil, cerca de 45 millones de personas poseen alguna deficiencia, de ese número, 26,5\% son mujeres y 21,2\% son hombres (IBGE, 2010). En la ciudad de Pelotas/RS para combatir esas adversidades y ayudar la populación deficiente fue creado en 1992 el Conselho Municipal de Direitos da Pessoa com Deficiência e Altas Habilidades, el primero del estado del Rio Grande do Sul y el segundo del Brasil. Dado el breve expuesto, la

\footnotetext{
${ }^{1}$ Especialista em Gestão Pública Municipal (2018) - Universidade Federal do Pampa. Unipampa. Assistente Social (2016) pela Universidade Norte do Paraná - UNOPAR. Contato: marcos_jag2009@hotmail.com

2 Professor Adjunto do Curso de Administração da UNIPAMPA - Universidade Federal do Pampa. Doutor em Administração pelo PPGA/ EA/UFRGS - Programa de Pós-graduação em Administração da universidade Federal do Rio Grande do Sul (2018), possui mestrado pelo mesmo programa (2009). Bacharel em Administração pela UFSM - Universidade Federal de Santa (2005).
} 
presente pesquisa objetiva analizar como ocurre la actuación del Conselho Municipal de Direitos da Pessoa com Deficiência e Alta Habilidade de Pelotas, visando la garantía de los derechos de las personas con deficiencia, bien como su bien estar e cualidad de vida en el municipio. Para tal, nuestro estudio se concentra en un carácter cualitativo, en lo cual realizaremos una investigación por medio de entrevistas semiestruturadas a la presidencia del Consejo analizado. Así, teniendo como público-objetivo las personas con deficiencias de la ciudad de Pelotas, creemos que el Consejo garante/asegura sus derechos, proporcionando acceso a la sociedad, por medio de la garantía de la inclusión social, familiar, acceso al transporte, educación, salud, prioridad en atendimiento, seguranza, accesibilidad, programas asistenciales, vagas en el mercado de trabajo. Por fin, a lo largo de la pesquisa, descorreremos sobre los problemas enfrentados por el Consejo y sobre las mudanzas en la sociedad pelotense, visando derechos, ciudadanía e inclusión social de la persona con deficiencia.

Palabras-clave: Gestión pública; Consejo; Persona con deficiencia.

\begin{abstract}
In Brazil, about 45 million people have a disability, of this number, $26.5 \%$ are women and $21.2 \%$ are men (IBGE, 2010). In the city of Pelotas / RS to combat these adversities and help the disabled population, the Municipal Council for the Rights of Persons with Disabilities and High Skills was created in 1992, the first in the state of Rio Grande do Sul and the second in Brazil. Given the foregoing, this research aims to analyze how the performance of the Municipal Council of Rights of People with Disabilities and High Ability of Pelotas occurs, aiming at guaranteeing the rights of people with disabilities, as well as their welfare and quality of life in the municipality. To this end, our study focuses on a qualitative character, in which we will conduct an investigation through semi-structured interviews with the analyzed Council presidency. Thus, targeting people with disabilities in the city of Pelotas, we believe that the council guarantees them / secures their rights by providing access to society through ensuring social, family, access to transportation, education, health, priority in attendance, safety, accessibility, assistance programs, job vacancies and so on, Finally, throughout the research, we will discuss the problems faced by the Council and the changes in Pelotense society, aiming at rights, citizenship and social inclusion of people with disabilities.
\end{abstract}

Keywords: Public Management; Advice; Disabled Person.

\title{
1. Introdução
}

O Brasil é o maior país da América do Sul e Latina, contando com um território de, aproximadamente, 8.515.767,049 quilômetros quadrados $\left(\mathrm{km}^{2}\right)$ e uma população de com cerca de 207 milhões de pessoas (BANCO MUNDIAL, 2016). Dentre esse número de habitantes, segundo dados fornecidos pelo Governo Federal, cerca de 45 milhões de pessoas possuem alguma deficiência, o que equivale a $24 \%$ da população (BRASIL, 2016), dentre esse número, cerca de 25.800 .681 (26,5\%) são mulheres e 19.805.367 (21,2\%) são homens (IBGE, 2010), tendo como deficiências mais evidentes: visual, auditiva, motora ou mental ou intelectual.

Tendo por base os dados apresentados, direcionando nosso olhar para a Constituição Federal de 1988, vemos que em seu artigo 23 que compete a União, Distrito Federal, Estados e Municípios, “[...] cuidar da saúde e assistência pública, da proteção e garantia das pessoas portadoras de deficiência" (BRASIL, 1988); ademais, conforme o artigo 24, inciso 14, vemos que também compete à União, Estados e Distrito Federal, proteger e integrar 
socialmente as pessoas portadoras de deficiência (BRASIL, 1988).

No que tange aos municípios, ao longo da história, a expansão do Brasil resultou em um processo de descentralização desordenada, com o objetivo de fortalecer as finanças dos estados e municípios em relação ao governo federal (VELOSO et al., 2011, p. 13). Assim, os municípios começam a ser administrados por uma gestão pública municipal que é responsável pelos interesses públicos e pela prestação de serviço, sobretudo, aos munícipes. Conforme Motta e Moreira (2007, p. 07), "a gestão municipal pode ser afetada por mecanismos institucionais locais, conselhos setoriais, auditores institucionais externos e pela disputa eleitoral dos cargos locais ou em outras esferas de governo".

Com vistas a supervisionar as políticas públicas propostas pela gestão pública municipal são criados os Conselhos de Direitos, "espaços institucionais fundamentais para a construção democrática das políticas públicas e exercício da participação e legitimidade social” (PARANÁ, 2014, p. 14).

Dado o exposto, a presente pesquisa toma como contexto de investigação o município de Pelotas, cidade localizada no Rio Grande do Sul, em especifico o Conselho Municipal de Direitos da Pessoa com Deficiência e Altas Habilidades. Assim, objetivamos analisar como ocorre a atuação do Conselho Municipal de Direitos da Pessoa com Deficiência e Alta Habilidade de Pelotas, visando à garantia dos direitos das pessoas com deficiência, bem como seu bem estar e qualidade de vida no município. Em específico, pretendemos identificar quais políticas públicas existem para atender a comunidade deficiente pelotense; analisar as ações do Conselho para mobilizar a gestão municipal na consecução dessas políticas; refletir sobre o papel do Conselho para reivindicar as demandas das pessoas com deficiência de Pelotas.

Para alcançar os ditos objetivos, seguindo os postulados de Bogdan e Biklen (1994), essa pesquisa se classifica como uma investigação qualitativa, em que a fonte e coleta dos dados se dá em ambiente natural. Como instrumento de coleta de dados utilizaremos entrevistas semiestruturadas à presidência do Conselho Municipal de Direitos da Pessoa com Deficiência e Altas Habilidades de Pelotas.

Assim, tendo como público-alvo as pessoas com deficiências da cidade de Pelotas, acreditamos que o Conselho lhes garante/assegura seus direitos, proporcionando acesso à sociedade, por meio da garantia da inclusão social, familiar, acesso ao transporte, educação, saúde, prioridade em atendimento, segurança, acessibilidade, programas assistenciais, vagas no mercado de trabalho e etc. Logo, por meio dessa pesquisa, pretendemos descortinar esse tema no âmbito acadêmico e social, visto que tais problemáticas ainda são pouco exploradas e 
as políticas públicas poderiam ser mais efetivas.

\section{Referencial Teórico}

\subsection{Direitos e Enfrentamentos das Pessoas com Deficiência}

Como foi abordado durante a introdução, o Brasil possui altos índices de pessoas diagnosticadas com deficiência, entretanto, em nosso cotidiano, é comum vermos a falta de espaços adaptados, o que dificulta a circulação, acessibilidade e trânsito desses sujeitos. No Brasil, sobretudo no Rio Grande do Sul, segundo Fernandes (2014, p. 30-31), se faz necessário a criação de mecanismos e instrumentos que possam garantir a inclusão e equiparação dos sujeitos, criando oportunidades e espaços que todos possam compartilhar.

Em contrapartida, nota-se que as pessoas vivem um processo cultural e identitário que visa alcançar o padrão da normalidade como uma condição essencial para a vida humana, Fernandes (2009) afirma que "as pessoas vivem em seu meio social sob a égide de uma cultura de normalidade, que se desenvolve a partir de uma lógica dicotômica que divide os seres em: normais/anormais; iguais/diferentes; perfeitos/deficitários”. Pensando nesse viés, a pessoa com deficiência nunca terá espaço na sociedade em que vive, não podendo exercer seu direto de ir e vir, um vez que a sociedade não lhe possibilita condições para tal.

Consultando a cartilha dos direitos dessas pessoas, vemos que o conceito de deficiência se refere a "[...] qualquer comprometimento que afeta a integridade da pessoa [...]" (CARTILHA DA INCLUSÃO, 2000). Esses comprometimentos, podem afetar a locomoção, coordenação, fala, compreensão de informações, orientação espacial e percepção, etc. Além disso, a deficiência gera dificuldades ou impossibilidade de execução de atividades comuns às outras pessoas e, inclusive, resulta na dificuldade da manutenção de emprego.

Concordando com essa visão de incapacidade que reverbera em problemas como a dificuldade de conseguir emprego, a Classificação Internacional de Doenças (CID), considera os portadores de necessidades especiais como incapazes, conforme segue:

Os pacientes portadores de necessidades especiais: revisando os conceitos de incapacidade, deficiência e desvantagem. Salusvita, Bauru, v. 23, n. 1, p. 109-116, 2004. A CID-10 afirma que "as Deficiências - impairments - dizem respeito à perda ou anormalidade de estrutura ou função psicológica, fisiológica ou anatômica. Em princípio, as deficiências representam distúrbios no nível do órgão. (SILVA; PANHOCA; BLACHMAN, 2004). 
Como vemos, conforme o CID, as pessoas deficientes são alocadas em uma relação estrita com a anormalidade/incapacidade de funções psicológicas, fisiológicas ou anatômicas. A partir dessas afirmativas, vemos que os documentos também defendem e ajudam a propagar a busca pela anormalidade, uma vez que classificamos algo como anormal e os documentos confirmam essa anormalidade. No campo hipotético, a sociedade construiu uma "padronização" de algo que seja considerado normal e os cidadãos buscam estar o mais próximo possível disso.

A sociedade atual, com o advento das tecnologias digitais, as constituições de identidades fluidas, o reconhecimento de diferentes culturas e etc., está pronta para quebrar com a visão de igualdade, a padronização e um estereótipo perfeito em que os demais devem tentar alcançar. Atualmente, a luta pela igualdade deve retornar a luta pela diferença, no qual emerge de uma mudança de paradigma, visto que até determinado período histórico a luta pela igualdade se generalizou conscientizando a sociedade que todos eram iguais, entretanto, segundo os postulados de Pierucci (1999), os sujeitos não querem mais ser iguais e, sim, diferentes, buscando o direito à diferença cultural e o direito de ser, não se preocupando com uma padronização de igualdade.

Partindo dessa visão da busca pelo diferente, trazemos alguns tipos de deficiência elencados na Cartilha da Inclusão (2000), sendo eles: Deficiência Física, Deficiência Mental, Deficiência Visual e Deficiência Auditiva. Detalhadamente, a primeira se refere a mobilidade considerando a fala, lesões neurológicas, musculares, ortopédicas ou má formação congênita; a segunda, aludi a um atraso no desenvolvimento mental; a terceira indica algum tipo de limitação visual; a quarta menciona a perda total ou parcial da audição.

Na presente classificação dos tipos de deficiência, vemos que a Cartilha se foca em questões fisiológicas, mostrando os problemas que cada deficiência apresenta, não realizando nenhum tipo de referência de como a pessoa deveria ser e como ela é. Nesse âmbito, pensa-se no profissional que irá atender esse sujeito, visto que, como já falamos anteriormente, há especificidades sociais/médicas que necessitam de um olhar profissional mais atento.

$\mathrm{O}$ assistente social, pessoa encarregada por fazer tal acompanhamento ao deficiente $^{3}$, através da Lei N 8.742/1993, que trata da Lei Orgânica de Assistência Social,

\footnotetext{
${ }^{3}$ Salientamos que o acompanhamento que o assistente social realiza não é somente destinado a deficientes e, sim, a todos os cidadãos.
} 
dispõe das seguintes orientações: o art. $1^{\circ}$ dispõe " [...] de um conjunto integrado de ações de iniciativa pública e da sociedade, para garantir o atendimento às necessidades básicas" (BRASIL, 1993); o art. 2º aborda que os objetivos da profissão visam “[...] a proteção social, que visa à garantia da vida, à redução de danos e à prevenção da incidência de riscos [...]” (BRASIL, 1993)., esses objetivos contemplam “[ [...] a proteção à família, à maternidade, à infância, à adolescência e à velhice” (BRASIL, 1993). Ademais, os assistentes sociais, dentre outras funções, atuam com crianças, adolescentes, no amparo a (re)habilitação de pessoas, em programas de benefícios com famílias e idosos, em casos de vulnerabilidade, ameaças e vitimização, políticas setoriais e etc. (BRASIL, 1993).

Como vimos na Lei, cabe ao assistente social garantir condições sociais básicas para sujeitos que necessitam de "proteção". Além disso, para que tais condições sejam oferecidas, cabe a União, Estados, Municípios e Distrito Federal, facultar convênios que com entidades e organizações para que as ações possam ser realizadas.

No que se refere as pessoas com deficiência, se a renda da família (per capita) for de até um quarto (1/4) de salário mínimo, é direito dela receber um benefício assistencial nãocontributivo, tendo em vista que, em tese, ela pode ser incapacitada de realizar trabalhos laborais e ser dependente de familiares (BRASIL, 1993). Além disso, a pessoa com deficiência tem o direito de receber um Benefício de Prestação Continuada da Assistência Social (BPC).

O BPC é um auxílio mensal e individual de um salário mínimo que se destina a idosos e pessoas com deficiência que não têm condições de se sustentar, não sendo necessário contribuição à Previdência Social para ter direito a receber. Sua operacionalização é de responsabilidade do Instituto Nacional do Seguro Social (INSS) e sua gestão fica a cargo do Ministério do Desenvolvimento Social e Combate à Fome (MDS).

A pessoa com deficiência, para receber tal benefício deve passar por uma avaliação médica e social que comprovará a necessidade do sujeito em receber o auxílio. Caso, durante o período de recebimento, o sujeito começar a exercer atividades laborais, pode-se solicitar a suspensão do valor e, requerê-lo novamente em caso de desemprego (após o recebimento do seguro desemprego).

\subsubsection{O Papel da Gestão Pública na Cidade de Pelotas/RS}


A cidade de Pelotas é um município localizado na região sul do Rio Grande do Sul, cerca de $260 \mathrm{~km}$ da capital Porto Alegre. De acordo com o último censo, 2010, disponibilizado pelo IBGE, o município conta com 328.275 habitantes e cerca de 14,5\% dessa população possui algum tipo de deficiência.

Devido esse número de pessoas com deficiência, vemos que a gestão do município, em tese, deveria garantir a tais cidadãos, direito de "[...] liberdade de deslocamento, através de mobilidade intermodal (vários sistemas de transporte integrados) sustentável, orientação informativa de percursos e pontos específicos de utilidade e uso público" (PORTO ALEGRE, 2010), entretanto, assim como em outras cidades brasileiras, o acesso para esses sujeitos é precário e, em alguns pontos, inviável, dificultando o processo de inclusão e construção de uma sociedade que vise os direitos e deveres de todos e, além disso, propicie o direito à saúde, trabalho, educação, cultura, lazer e etc. (PORTO ALEGRE, 2010).

Segundo Brasil (2015), no País há uma gama de projetos, Leis e Decretos que amparam as gestões municipais no que se refere ao desenvolvimento de projetos, adequação e acessibilidade urbana para todos, mas, como vemos, na cidade, há poucos espaços públicos e locais que sejam acessíveis.

[...] os governos municipais têm muita dificuldade em planejar, executar e fiscalizar as ações voltadas à acessibilidade, pois não contam com orientações corretas e muito menos com ferramentas de coordenação administrativa que possam dinamizar os trabalhos. Com isso, o município desperdiça recursos, a iniciativa privada não percebe seus esforços recompensados e as obras e serviços disponibilizados à sociedade continuam a não atender as necessidades das pessoas com deficiência ou mobilidade reduzida. (BRASIL, 2015, p. 17)

No que se refere a cidade de Pelotas, em 1992 foi criado o Conselho Municipal dos Direitos das Pessoas Portadoras de Deficiência e Superdotados, por meio da Lei $\mathrm{n}^{\circ} 3.551$, de 02 de julho de 1992, que dispõe sobre a política municipal dos direitos das pessoas portadoras de deficiência e superdotados. Segundo o seu Artigo (Art.) 2 ${ }^{\circ}$, vemos que os direitos de pessoas deficientes na cidade de Pelotas será realizado através de Políticas Sociais Básicas de Educação, Saúde, Recreação, Esporte, Cultura, Profissionalização e etc., tendo como ponto principal o respeito, liberdade e a convivência, sendo ela familiar ou comunitária (PELOTAS, 1992). Sendo assim, as competências do Conselho são as seguintes:

I - Formular a Política Municipal dos Direitos das Pessoas Portadoras de Deficiência e dos Superdotados, [...] II - Zelar pela execução dessa Política [...] III - Formular as prioridades a serem incluídas no planejamento do Município, [...] 


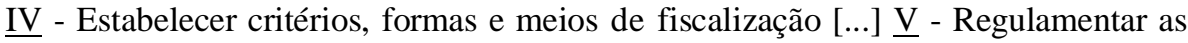
entidades não governamentais de atendimento dos direitos das pessoas porta doras de Deficiência e Superdotadas. VI - Regulamentar, organizar, coordenar, bem como adotar todas as providências que julga cabíveis para a eleição e a posse dos membros do Conselho. (PELOTAS, 1992).

Quando foi criado, o Conselho era comporto por 10 membros, cinco membros de entidade que compõem órgãos públicos e cinco membros de entidades que atuavam na área da pessoa com deficiência, entretanto, em 2012 a Lei 3.551 foi revogada/reformulada e passou a vigorar no município a Lei 5.869, de 04 de janeiro de 2012, com nova denominação Política dos Direitos da Pessoa com Deficiência e Altas Habilidades, que sistematiza os membros e suas funções. Na nova Lei o Conselho é composto por um total de 16 membros, não remunerados, sendo oito representantes do município, indicados pelos seguintes órgãos: Gerência Regional do INSS de Pelotas, Gerência Regional Trabalho e Emprego de Pelotas, Secretaria Municipal de Cidadania e Assistência Social, Secretaria Municipal de Educação e Desportos, Secretaria Municipal de Saúde, Secretaria Municipal de Segurança, Transporte e Trânsito, $17^{\mathrm{a}}$ Coordenadoria Regional do STDS, 5 Coordenadoria Regional de Educação.

O restante dos membros são indicados pelas seguintes organizações: Quatro são indicados por organizações que prestam atendimentos especializado na área da pessoa com deficiência e altas habilidades e os outros quarto são indicados por organizações de usuários da área da pessoa com deficiência e altas habilidades.

Com base explanação vemos que os sujeitos deficientes no contexto da nossa pesquisa, cidade de Pelotas, possuem um Conselho Municipal devidamente organizado e composto por representantes de diversas instâncias governamentais que defendem seus direitos e procuram proporcioná-los um espaço cada vez mais acessível.

\section{Método}

Com vistas a alcançarmos o nosso objetivo, a pesquisa apresentará, de caráter qualitativo, se embasará na metodologia de estudo de caso. Segundo Gil (2008), o estudo de caso se refere a um exaustivo estudo que leva em consideração uma ampla compreensão sobre o assunto/tema investigado. De modo mais detalhado, Severino (2007, p. 121), aborda que o "estudo de caso é uma pesquisa que [...] se concentra no estudo de um caso particular, considerado representativo de um conjunto de casos análogos, por ele significativamente representativo". A coleta dos dados e sua análise se dão da mesma forma que nas pesquisas 
de campo, em geral.

Com base nesse método, dividimos a pesquisa em dois momentos, o primeiro será destinado a elaboração de entrevistas semiestruturadas que serão aplicadas ao vicepresidente do Conselho Municipal da Pessoa com Deficiência e Altas Habilidades de Pelotas. Conforme Gray (2012, p. 302), “as entrevistas semiestruturadas não são padronizadas e muitas vezes são usadas na análise qualitativa”.

Para o autor, em uma entrevista semiestruturada o entrevistador elabora um guia com perguntas que serão norteadoras na conversa, entretanto, o pesquisador é livre para mudar a ordem das questões, como também inserir outras questões. Em resumo, tudo dependerá das respostas que serão dadas, “[...] o objetivo é explorar os sentidos subjetivos que os respondentes atribuem a conceitos ou eventos" (GRAY, 2012, p. 302).

Tais entrevistas terão como foco o papel do Conselho no que se refere às pessoas com deficiência, tendo em vista as suas atividades junto a sociedade de Pelotas, à garantia dos direitos das pessoas com deficiência, bem como seu bem estar e qualidade de vida desses sujeitos no município.

A primeira entrevista foi realizada com o vice-presidente do conselho, no qual, primeiramente, o deixamos livre para se apresentar, além de apresentar a história e informações gerais de como funciona e qual o papel central do Conselho no município. Logo após, realizamos as seguintes perguntas: 1) O Conselho possui fundo?; 2) A assistência social participa do Conselho?; 3) Quantos membros o Conselho possui atualmente?; 4) O Conselho possui uma eleição para a escolha de sua diretoria?; 5) Quem é que pode votar nas eleições do Conselho?; 6) A atuação no Conselho é de caráter voluntário?; 7) Qual o objetivo do Conselho?; 8) A gestão pública municipal contribui com o Conselho?; 9) Como é feita a orientação do Conselho sobre o mercado de trabalho e os benefícios?; 10) Com a criação do Conselho, você vê, positivamente, a questão do mercado de trabalho para deficientes?.

A segunda entrevista será realizada à secretária do Conselho, no qual, primeiramente, perguntaremos o seu nome e sua função junto com Conselho e, logo, seguiremos um roteiro com as seguintes perguntas: 1) Como conheceu o Conselho e como você chegou ao Conselho?; 2) Há quanto tempo atuas no Conselho?; 3) Sua experiência no Conselho, na prática, foi positiva?; 4) Nas suas palavras, como o Conselho se organiza e como se dá o seu funcionamento?; 5) O Conselho possui assistente social que participe de suas funções? Qual seu papel?; 6) Você acha que se tivesse um profissional de serviço social destinado somente para o Conselho seria mais proveitoso?; 7) Como você avalia, 
atualmente, o papel da gestão pública junto ao Conselho?. 8) Há alguma regra ou norma que os membros devem seguir?; 9) De que forma a gestão púbica municipal se articula com o Conselho?; 10) As demandas do Conselho são atendidas pela gestão municipal?; 11) Você acha que o Conselho contribui com a sociedade?.

Após a conclusão das entrevistas, passamos para a segunda etapa da pesquisa, a de análise e reflexão dos dados obtidos. Nessa fase, pretendemos refletir sobre as reais ações e problemas que o Conselho Municipal da Pessoa com Deficiência e Altas Habilidades de Pelotas enfrenta, articulando os dados coletados com a Lei Municipal 5.869, de 04 de janeiro de 2012.

\section{Resultados e Discussão}

Com base no que foi exposto até o momento, vemos que o Conselho Municipal de Direitos da Pessoa com Deficiência e Alta Habilidade de Pelotas atua ininterruptamente desde o ano de 1992, perfazendo 26 de luta e contribuição, buscando uma melhor qualidade de vida para as pessoas com deficiências e altas habilidades e, sobretudo, para os munícipes de Pelotas. Cabe ressaltar que este é o primeiro Conselho implantado no Rio Grande do Sul e o segundo no Brasil.

Como já foi abordado anteriormente, o estudo foi realizado por meio de entrevistas ao vice-presidente do Conselho e sua secretária. Em um primeiro momento foi-nos apresentado uma pequena trajetória histórica do Conselho, abordando que a sua primeira equipe de trabalho, constituída para a sua fundação em 1992, continha 10 membros, sendo 5 representantes de órgãos públicos e 5 profissionais que se dedicavam a ações direcionadas as pessoas com deficiência. A partir dessa fundação, as reuniões ocorriam na câmara de vereadores, passando, posteriormente, para o Centro de Reabilitação de Pelotas (CERENEPE) e, por fim, por volta do ano 2002, foi criada no município a Casa dos Conselhos, no qual foi disponibilizado um espaço adaptável e, desde então, o Conselho da Pessoa com Deficiência e Alta Habilidade realiza suas reuniões e atividades nesse espaço.

Ademais, a criação do Conselho, em um primeiro momento, serve para reivindicar, visando as prerrogativas constitucionais que visam a criação e ampliação de espaços sociais destinados a formação e estruturação de uma agenda para o poder público (BRASIL, 1988), que as pessoas com deficiência também sejam contempladas nesses espaços visto que somos representados por uma gestão democrática participativa que, em tese, deveria contemplar todos os sujeitos em seus projetos (SALLES, 2010). Para Villela et. al (2016, p. 
622), essa visão participativa vai ao encontro as atividades desenvolvidas pelo Ministério das Cidades, no qual visa "estimular a ampliação e o aperfeiçoamento dos mecanismos de participação social" (VILLELA et. al, 2016, p. 622).

Dividimos nossa entrevista em três momentos que correspondem aos seguintes subtítulos: Políticas públicas voltadas à comunidade deficiente pelotense; Ações do Conselho para garantir os direitos dos pelotenses com deficiência; Papel do Conselho na reivindicação das demandas dos pelotenses com deficiência. A seguir, com base nas entrevistas, realizaremos as discussões.

Abaixo uma foto dos entrevistados: vice-presidente Sidnei Fagundes, à direita a secretária Daiane Machado e no centro a presidente Brandina Oliveira Buttow, que não pôde ser entrevistada por motivos laborais.



Figura 1 - Diretoria do Conselho das Pessoas com Deficiência e Alta Habilidade (biênio 2018-2019). Fonte: Prefeitura de Pelotas (2018). ${ }^{4}$

\subsection{Políticas Públicas Voltadas à Comunidade Deficiente Pelotense}

Segundo o nosso entrevistado, o objetivo do Conselho é fiscalizar a prefeitura, os órgãos públicos, sugerir propostas, acompanhar a legislação existente e ser protagonista no que se refere a propostas de legislação. Como vemos, conforme os objetivos citados pelo entrevistado, o Conselho é um órgão com poder deliberativo, de acordo com legislação vigente, editada em 2012, destacamos as competências dispostas na Lei municipal 5.8695:

\footnotetext{
${ }^{4}$ Disponível em: http://pelotas.rs.gov.br/noticia/eleita-nova-diretoria-do-conselho-das-pessoas-com-deficienciae-altas- habilidades. Acesso em 04 de abril de 2019.

${ }^{5}$ Cabe ressaltar que um dos motivos do Conselho ter atualizado/ampliado a Lei se deu pela mudança da nomenclatura das pessoas com deficiência, uma vez, primeiramente elas eram chamadas de pessoas com
} 
I - Propor a política municipal dos direitos da pessoa com deficiência e altas habilidades, fixando as prioridades para a consecução das ações, a captação e a aplicação de recursos;

II - Zelar pela execução dessa política, atendidas as peculiaridades da pessoa com deficiência, de suas famílias e de seus grupos de vizinhanças; III - Propor as prioridades a serem incluídas no planejamento do Município, em tudo o que se refere ou possa afetar as condições de vida da pessoa com deficiência e altas habilidades;

IV - Estabelecer critérios, formas e meios de fiscalização em sua área de atuação; V - Propor na sua esfera formas para regulamentar as entidades não governamentais de atendimento dos direitos da pessoa com deficiência e altas habilidades; VI - Encaminhar ao Executivo proposta para regulamentar, organizar, coordenar, bem como adotar todas as providências que julga cabíveis para a eleição e a posse dos membros do Conselho (PELOTAS, 2012).

Pela prerrogativa legal, podemos aferir uma parte significativa da sua importância, visto que há uma Lei específica para embasar as ações propostas pelos agentes do Conselho.

Com base nesses objetivos, segundo o entrevistado, os conselheiros se reúnem uma vez por mês para avaliar como estão sendo resolvidas as problemáticas, solicitações realizadas e debater a fiscalização dos órgãos públicos. $\mathrm{O}$ vice-presidente ainda ressalta que a Lei e a Legislação que se refere as pessoas com deficiência abrange várias questões importantes, entretanto o Conselho deve realizar essa ponte para que ela seja cumprida.

Conforme os postulados de Malmegrin (2010), vemos que as ações podem ser vistas como uma rede, ou seja, uma organização pública de cooperação local, no qual diversos setores, profissionais organizações e atores sociais, tecem redes colaborativas, compartilhando as necessidades das entidades onde atuam e apoiam as demandas dos demais conselheiros. Em resumo, são representantes de outros cidadãos, que no seu cotidiano necessitam de apoio e suporte para o desenvolvimento de suas atividades sociais, cognitivas, educativas e laborais. Nesse viés, o Conselho, segundo o vice-presidente, realiza um intercâmbio entre as secretarias do município, tecendo uma rede de integração e trabalho em conjunto. Atualmente, umas das lutas do Conselho refere-se ao transporte público, segundo o entrevistado, a cerca de quinze anos atrás Pelotas possuía cerca da 300 veículos destinados ao transporte público e, destes 300, somente 5 eram adaptáveis, visto que havia uma Lei que exigia que cada empresa deveria ter, no mínimo, 1 veículo adaptável, atualmente a Legislação foi alterada e Pelotas conta com cerca de 80 carros adaptáveis, mas esse número, conforme afirma o entrevistado, ainda é baixo, visto que a

necessidades especiais, pessoas portadoras de deficiência e, atualmente, o Brasil assumiu um compromisso com a ONU, aderindo o termo pessoas com deficiência, abrangendo os cinco tipos de deficiência: física, mental, visual, auditiva e a múltipla. O que define os tipos de deficiência é o CID. 
cidade também cresceu muito. Assim, uma das principais cobranças

feitas à prefeitura e órgãos públicos se refere a essa problemática.

Com relação ao mercado de trabalho, com a Lei 5.869, foi inserido no Conselho o Ministério do Trabalho e Emprego de Pelotas e o sistema Nacional de Emprego (SINE), ajudando na fiscalização de empresas que possuem acima de 100 funcionários, uma vez que elas são obrigadas a empregar pessoas com deficiência, e a grande maioria dessas vagas são ofertadas através o SINE. Também foi relatado que nos últimos anos foram empregados mais de 300 deficientes.

Um adendo de suma importância sobre a questão empregatícia dos deficientes se refere, novamente, ao transporte, visto que eles querem trabalhar, mas têm dificuldade em se transportar, já que há poucos ônibus adaptados e, muitas vezes, eles ficam na parada esperando e não podem entrar em vários ônibus que vão para o destino pretendido, pois os veículos não têm recursos para transportá-los.

\subsection{Ações do Conselho para Garantir os Direitos dos Pelotenses com Deficiência}

Durante a entrevista, o vice-presidente do Conselho aborda que há vários representantes das secretarias municipais em cargos de representação, logo, o Conselho conta com vários profissionais envolvidos. Em outra entrevista realizada à secretária do Conselho, tal informação é reafirmada, entretanto ela ressalta que tais profissionais somente participam das reuniões, não auxiliando nas ações que são desenvolvidas.

Quando a secretária é questionada se o Conselho dispõe de um assistente social, por exemplo, é relatado que sim, que há um assistente social nos cargos de representação municipal, mas tal sujeito só comparece nas reuniões mensais, não auxiliando nas atividades que o Conselho propõe para as pessoas com deficiência. Diante disso, salientamos que, no geral, os deficientes que necessitam de algum auxílio especifico são encaminhados para as secretarias, mas, no Conselho, não há nenhum profissional designado pela prefeitura para atender/auxiliar esses sujeitos.

Dentre outras ações realizadas, podemos destacar que o Conselho realiza cursos de capacitação profissional e ofertas no mercado de trabalho, através dos programas de cotas para pessoas com deficiência. Esta ação destinada a reservas de vagas para pessoas com deficiência é operacionalizada através da Fundação Gaúcha de Trabalho e Ação Social/SINE. Tal iniciativa surgiu visto que é obrigatoriedade das empresas empregar pessoas deficientes e, diante dessa demanda, o Conselho notou que muitos deficientes não 
possuíam experiência profissional, tampouco cursos de aperfeiçoamento.

\subsection{Papel do Conselho na Reivindicação das Demandas dos Pelotenses com Deficiência}

Durante a entrevista realizada com a secretária do Conselho, vemos, por meio de seus relatos que o seu trabalho é extremamente precarizado. Foi-nos relatado que o Conselho possui um fundo, entretanto só pode ser usado em despesas estruturais para o prédio, não é possível usar este dinheiro para produção de materiais de divulgação de ações (folder), para camisetas para que os voluntários que trabalham no Conselho sejam identificados, e materiais informacionais para que a sociedade conheça o Conselho e saiba a quem deve se reportar em caso necessite. Nesse viés, um exemplo citado por ambos os entrevistados foi a impossibilidade de registrar as atas das reuniões em livro ata, pois devido as burocracias da prefeitura, ainda não foi liberado a verba para a compra do livro referente ao ano de 2018.

A secretária salienta que seria mais viável que o Conselho tivesse autonomia de administrar a sua própria verba, sem necessitar passar por tramites políticos e administrativos, assim, seria mais viável a execução de determinadas ações e benfeitorias.

Entre as ações que o Conselho conseguiu elaborar com o apoio da Prefeitura Municipal de Pelotas, a Secretaria Municipal de Assistência Social e a Casa dos Concelhos foi a $19^{a}$ Semana Municipal da Pessoa com Deficiência, realizada em 2018. Segue o folder de divulgação.
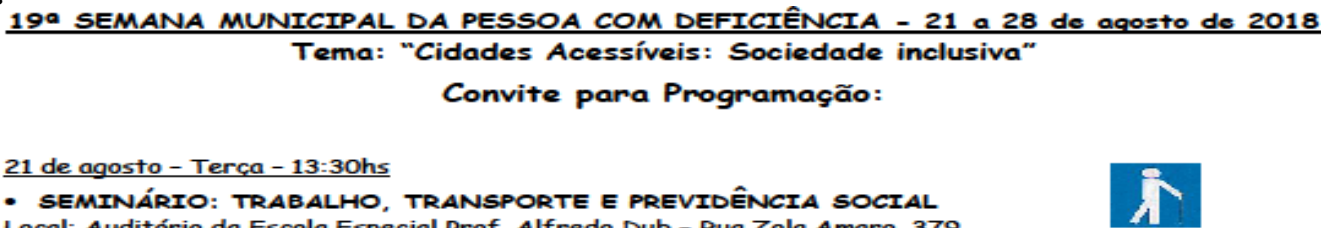


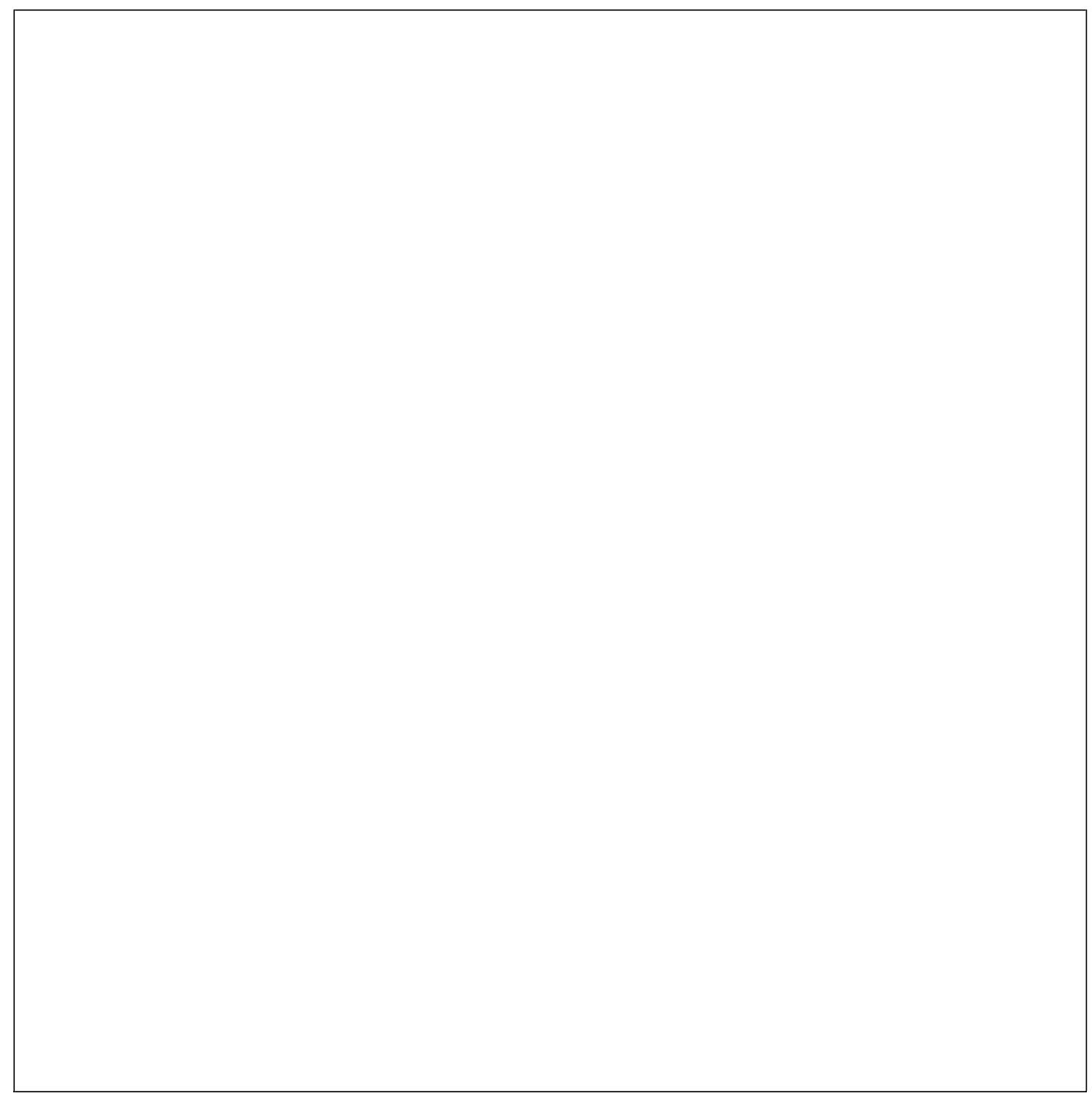

Figura 2 - Divulgação 19ª Semana Municipal da Pessoa com Deficiência de Pelotas - 2018

Fonte: Conselho Municipal dos Direitos da Pessoa com Deficiência e Altas Habilidades (2018)

Notamos que o tema da semana se refere à acessibilidade, como foi abordado anteriormente, uma problemática que está sempre em pauta no município, visto que há um número baixo de veículos acessíveis. A mobilidade urbana em Pelotas é um grande problema, pois os deslocamentos dependem, muitas vezes, de transporte público que raramente possuem adaptação.

Assim, acreditamos que essa semana teve como objetivo despertar a sociedade para esses problemas, de modo a lutar e reafirmar que as pessoas com deficiência também têm o direito de ir e vir, ter acesso a todos os lugares, morar, trabalhar, ter lazer e etc. Para que isso ocorra é preciso que haja a ampliação da acessibilidade municipal, no espaço público, no privado, em ambientes de trabalho e no transporte público. Segundo a Fundação 
de Articulação e Desenvolvimento de Políticas Públicas para Pessoas com Deficiência e com Altas Habilidades no Rio Grande do Sul, FADERS - RS,

\begin{abstract}
Acessibilidade é um substantivo que denota a qualidade de ser acessível; "acessível", por sua vez, é um adjetivo que indica aquilo a que se pode chegar facilmente, que fica ao alcance. Alcançar acessibilidade significa conseguir a equiparação de oportunidades em todas as esferas da vida. Isso porque essas condições estão relacionadas ao AMBIENTE e não às características da pessoa. Adequação das vias e dos espaços públicos: mobiliário urbano, construção e reforma de edifícios, meios de transporte e comunicação, bem como acesso à informação (FADERS, 2018, p. 02).
\end{abstract}

Em 2018, identificamos a proposta de criação de um plano de mobilidade urbana em Pelotas, no qual foi realizada uma reunião com a gestão pública municipal, envolvendo o Conselho das Pessoas com Deficiência e outro correlato, com vistas a buscar atendimento e um seguimento para sujeitos que, eventualmente, podem adquirir mobilidade reduzida - o Conselho dos Idosos. O encontro foi realizado, sob a coordenação da Secretaria de Transporte e Trânsito e contou com cerca de 30 pessoas. A seguir alguns assuntos elencados na reunião.

[...] os presentes puderam conversar e elencar os principais problemas que identificam no trânsito e transporte de Pelotas. Um dos grupos, representado pela assistente social da Associação Escola Louis Braille, Juliana Matos Ferreira, destacou a necessidade de melhorias na iluminação pública e na sinalização de obras, além da colocação de sinal sonoro nos semáforos [...]. Manutenção de pisos táteis [...] Implementação de mais rampas de acesso, requalificação de calçadas para facilitar o embarque e desembarque no transporte coletivo e alinhamento de faixas de travessias de pedestres às rampas de acessibilidade (PELOTAS, 2018).

Do exposto, o trabalho identificou, no diálogo entre a base empírica e a teórica, um cenário positivo visto que desde 1988 há um posicionamento governamental que busca a inclusão de pessoas com deficiência na esfera das políticas públicas. Ademais, vemos que há outros marcos legais criados ao longo dos anos, como a Lei Brasileira de Inclusão da Pessoa com Deficiência (Estatuto da Pessoa com Deficiência) Lei n. 13.146/2015.

Conforme os postulados de Sousa, Fischer e Vanconcellos (2015, p. 96), os conselhos, ao longo dos anos, se constituíram como um meio de desenvolvimento de ações capazes de ampliar a interlocução interinstitucional e interescalar. Tais ações, reverberam em impactos escalares nacionais, regionais e municipais, no qual "envolve um processo de mudança social nas relações entre agentes e territórios (organizações, instituições e políticas), por meio de parâmetro endógeno, que envolve estruturas e processos relacionais em diversas instâncias e níveis [...]" (SOUSA; FISCHER; VASCONCELLOS, 2015, p. 96). A partir dessas discussões vemos que um conselho se forma por sujeitos que atuam em diversos ramos com vistas a discutir a partir de diferentes visões e pensar em ações amplas 
e direcionadas a vários segmentos.

Durante a investigação, percebemos que um dos maiores problemas de inclusão no município se dá por causa da falta de recursos para a mobilidade. A cidade de Pelotas, devido a sua arquitetura, torna-se, em alguns espaços, inacessível, entretanto, por mediação do Conselho, ocorreram muitos avanços, buscando espaços adaptados que devem fazer parte do planejamento urbano municipal, o que Pinheiro (2010) nomeia como "Plano Diretor e Gestão Urbana".

Através do olhar atento para as políticas públicas que se pode pensar em uma gestão municipal mais eficiente e, desta forma, este é um dos papéis do Conselho, o de acompanhar, registrar, solicitar, fiscalizar e propor, primando por uma gestão pública transparente, onde o cidadão possa estar presente e, dentre o possível, ser contemplado em suas demandas. De modo geral, no que se refere ao nosso campo de estudo, nossos entrevistados afirmam que a atuação do Conselho é satisfatória, pois eles se consideram um grupo que atua de forma organizada, realizando reuniões mensais, geralmente, nas segundas terças-feiras de cada mês, que são discutidos temas que abrangem o município e que possuem intersecção com a legislação estadual e federal.

\section{Conclusões}

Ao decorrer das discussões realizadas, nosso intento foi o de analisar como ocorre a atuação do Conselho Municipal de Direitos da Pessoa com Deficiência e Alta Habilidade de Pelotas, visando à garantia dos direitos das pessoas com deficiência, bem como seu bemestar e qualidade de vida no município. Para que tal objetivo fosse alcançado, além do referencial teórico discutido e da legislação consultada, realizamos entrevistas com os responsáveis pelo Conselho, a fim de dar voz para os seus representantes.

Como foi discutido ao longo do nosso texto, o Conselho investigado foi o primeiro a ser implantado no estado do Rio Grande do Sul destinado a propor políticas e atender as pessoas com deficiência e alta habilidade. Em âmbito, nacional ele foi o segundo a ser criado para tais fins, conforme o seu vice-presidente, quando o Conselho iniciou suas atividades passou por várias dificuldades, desenvolvendo suas atividades em sedes provisórias até que foram alojados na Casa dos Conselhos, em Pelotas, no qual dispõem de um espaço com adaptação adequada para desenvolver seus trabalhos e recepcionar seu público-alvo.

Como vimos nas análises das entrevistas realizadas, embora o Conselho tenha uma sala adaptável que corrobora para o acesso dos membros e da população atendida, ele ainda 
passa por dificuldades, sobretudo no que se refere ao fundo monetário destinado as despesas. O fundo destinado ao Conselho só pode ser usado para a compra de materiais de expediente, por meio de licitação com o orçamento de três empresas que vendem o produto desejado, em decorrência disso, os membros do Conselho alegam ter dificuldade para adquirir alguns materiais e, além disso, gostaria de aplicar esse fundo em outras ações como, por exemplo, eventos, atividades de conscientização à sociedade, atividades destinadas aos deficientes e etc. Ademais, uma das maiores reinvindicações com relação ao fundo é o desejo dos membros em utilizá-lo para divulgar as atividades e identificação dos envolvidos, destinando parte do valor para a produção de folders, broches e camisetas.

Além dos problemas financeiros, o Conselho também enfrenta alguns problemas de cunho social, sobretudo no que se refere a acessibilidade no município de Pelotas, uma vez que, seu projeto arquitetônico inviabiliza, em alguns pontos, a execução de obras para garantir o acesso aos deficientes em todos os espaços. Acreditamos que a gestão pública municipal, juntamente com as demais gestões, estatual e federal, teriam que repensar e articular novo projeto que pudesse ser aplicado, a fim de possibilitar um maior acesso.

Outro ponto que devemos chamar atenção sobre os resultados das análises das entrevistas foi para o transporte púbico de Pelotas, visto que há poucos ônibus públicos adaptáveis para as pessoas com deficiência. Tal problemática impede a locomoção dos deficientes no perímetro urbano da cidade, dificultando que elas tenham acesso à saúde, educação, lazer e ingresso no mercado de trabalho, visto que com poucos ônibus à disposição da população com deficiência os seus direitos estão sendo negados. A exemplo, na reunião mensal que assistimos um dos membros chegou atrasado, pois ele aguardava o transporte adaptado para suas necessidades e teve que esperar na parada até que, dentre os vários ônibus que passaram, passasse um ônibus adaptado.

Ademais desse problema com o transporte, identificamos uma falta profissional no Conselho para, assim como é feito pelos voluntários, auxiliar no encaminhamento de demandas. Como o transporte público adaptável na cidade não é frequente, seria de suma importância a presença de, por exemplo, um assistente social no local para atender os deficientes e ajuda-los no encaminhamento das documentações para solicitar auxílio e etc. Geralmente, eles vão até o Conselho para se informar sobre os passos que devem tomar para o encaminhamento do dito auxílio, posteriormente entram em contato com o assistente social do seu bairro para carimbar o pedido e, por fim, são atendidos e conseguem encaminhar a documentação. Se houvesse um assistente social no Conselho isso poderia ser resolvido de maneira mais fácil, visto que toda a documentação ficaria pronta no local. 
Ao longo da pesquisa mostramos um espaço novo que luta incansavelmente para proporcionar, sobretudo aos deficientes de Pelotas, uma melhor qualidade de vida e social. Como vimos ao decorrer do texto, ainda há muitas questões a serem pensadas juntamente com a gestão pública municipal a fim de articular, desenvolver, avaliar e aplicar novas estratégias de interesse público para apurar soluções e resolver problemas como a acessibilidade e a garantia de direitos mínimos de inclusão, cidadania e bem-estar das pessoas com deficiência e seus familiares.

Por fim, ao longo de seus 26 anos de funcionamento o Conselho conquistou muitas mudanças na sociedade pelotense, visando direitos, cidadania e inclusão social da pessoa com deficiência, entretanto, o combate por uma sociedade mais inclusiva e receptiva as diferentes deficiências ainda é constante.

\section{Referências}

BANCO MUNDIAL. Brasil. Disponível em: <https://data.worldbank.org/country/brazil?locale=pt>. Acesso em: 08 ago. 2018.

BOGDAN, R.; BIKLEN, S. Investigação qualitativa em educação: uma introdução à teoria e aos métodos. Porto: Proto Editora, 1994.

BRASIL. Constituição da República Federativa do Brasil. Brasília, DF: Senado Federal: Centro Gráfico, 1988.

Lei n. 8.742, de 07 de dezembro de 1993. Lei Orgânica da assistência Social (LOAS) que dispõe sobre a organização da Assistência Social e dá outras providências, e legislação correlata. Brasília: Câmara dos Deputados.

. Cresce número de pessoas com deficiência no mercado de trabalho formal. Disponível em: <http://www.brasil.gov.br/economia-e-emprego/2016/09/cresce-numerode- pessoas-com-deficiencia-no-mercado-de-trabalho-formal>. Acesso em: 08 ago. 2018.

. Cartilha do Censo 2010: dessoas com deficiência. Disponível em:

<http://www.pessoacomdeficiencia.gov.br/app/sites/default/files/publicacoes/cartilhacenso- 2010-pessoas-com-deficienciareduzido.pdf>. Acesso em: 08 ago. 2018.

Brasil Acessível: programa brasileiro de acessibilidade urbana. Disponível em: <http://www.secid.ma.gov.br/files/2015/03/BrasilAcessivelCaderno04.pdf>. Acesso em: 05 set. 2018.

CARTILHA DA INCLUSÃO. Dos Direitos das Pessoas com Deficiência. Disponível em: 
<http://www.grandesencontros.com.br/CartilhaInclu2.htm>. Acesso em: 20 ago. 2018.

FADERS. Atitudes que Fazem a Diferença com PCD: garantir os direitos humanos é o caminho para a inclusão. Disponível em:

<http://www.portaldeacessibilidade.rs.gov.br/uploads/1427723364Cartilha_Faders_word_ co m_novo_layout.pdf>. Acesso em 30 set. 2018.

FERNANDES, I. A Pesquisa: condições de acesso das pessoas com deficiência aos bens sociais do estado do Rio Grande do Sul. In: CASTRO, C. M. F. de; FERNANDES, I.; AZEVEDO, R. A. de. Condições de Acesso das pessoas com deficiência aos bens sociais do Estado do Rio Grande do Sul. Porto Alegre: Efangraf, 2014. . Sociologia da acessibilidade. Curitiba: Editora Ibpex. 2009.

GIL, A. C. Métodos e técnicas de pesquisa social. São Paulo, Atlas, 2008. GRAY, D. E. Pesquisa no mundo real. Porto Alegre: Penso, 2012.

MOTTA, R. S. da; MOREIRA, A. Eficiência na gestão municipal no Brasil. Disponível em: <http://www.en.ipea.gov.br/agencia/images/stories/PDFs/TDs/td_1301.pdf>. Acesso em: 09 ago. 2018.

MALMEGRIN, M. L. Redes públicas de cooperação local. Florianópolis. CAPES. UAB. 2010.

PARANÁ. Conselhos de Direito. Disponível em:

<http://www.dedihc.pr.gov.br/modules/conteudo/conteudo.php?conteudo=9>. Acesso em: 09 ago. 2018.

PELOTAS. Lei n. 3551, de 02 de julho de 1992. Dispõe sobre a política municipal dos direitos das pessoas portadoras de deficiência e superdotados. Pelotas: Câmara Municipal de Pelotas.

. Lei 5.869, de 04 de janeiro de 2012. Dispõe sobre a Política Municipal dos Direitos da Pessoa com Deficiências e Altas Habilidades, e dá outras providências. Pelotas: Câmara Municipal de Pelotas.

$12^{a}$ Consulta sobre Mobilidade ocorre na Casa dos Conselhos. Disponível em:

<http://www.pelotas.com.br/noticia/12a-consulta-sobre-mobilidade-ocorre-na-casados- conselhos>. Acesso em: 30 set. 2018.

PIERUCCI, A. F. Ciladas da diferença. São Paulo: Editora 34, 1999.

PINHEIRO, O. M. Plano diretor e gestão urbana. Florianópolis: Departamento de Ciências da Administração/UFSC; [Brasília]: CAPES/UAB, 2010. 
SALLES, et al. Acessibilidade arquitetônica interfere na usabilidade de indivíduos com mobilidade reduzida?. Revista de Terapia Ocupacional da Universidade [oline]. São Paulo, v. 21, n. 1, p. 83-88, jan./abr.2010.

SEVERINO, A. J. Metodologia do trabalho científico. São Paulo: Cortez, 2007.

SILVA, O. M. P. da; PANHOCA, L.; BLACHMAN, I. T. Os pacientes portadores de necessidades especiais: revisando os conceitos de incapacidade, deficiência e desvantagem. Salusvita, v. 23, n. 1, p. 109-116, 2004.

SOUSA, Y. M.; FISCHER, T. M. D.; VASCONCELLOS, A. M. DE A. Os conselhos municipais e o MROSC enquanto instrumentos democratizantes para transformações políticas e desenvolvimento local. Amazônia, Organizações e Sustentabilidade, vol. 4, n. 1, 2015.

VILLELA, L. E.; et al. A conferência nacional das cidades como instrumento de políticas públicas para o desenvolvimento territorial: a percepção dos conselheiros nos processos participativos e deliberativos. Cadernos EBAPE.BR [online], v.14, p.619639, 2016.

VELOSO, J. F. A. et al. Uma visão inicial dos subsistemas da gestão municipal. In: VELOSO, João F. A. (Org.). Gestão Municipal no Brasil: um retrato das prefeituras. Brasília: Ipea, 2011. p. 11-39. 